\title{
Formation of a Corporate Culture Conducive to the Implementation of Breakthrough Innovative Projects
}

\begin{abstract}
Islam Sulumov ${ }^{1}{ }^{*}$ Zulay Tavbulatova $^{1}$
${ }^{1}$ Chechen State University, Russia

"Email: sulumof@gmail.com

ABSTRACT

Radical innovations are characterized by the fact that they lead to the formation of new markets, while the old ones cease to exist. Their development requires specific cultural characteristics of organizations. The purpose of the study is to identify the features of organizational culture that favor radical innovation. To do this, the following tasks will be solved: identifying the companies that are most actively and consistently implementing breakthrough innovative projects; identifying the key parameters of organizational culture that have the greatest impact on organizational activity; analyzing the organizational culture of companies according to these parameters in order to identify their common cultural features. The veracity of the deduced hypotheses will be evaluated using the Bernoulli mathematical formula. The results of the study can be used in the formation of organizational culture components by organizations seeking to implement radical innovative projects.
\end{abstract}

Keywords: Radical innovation, Disruptive technology, Organizational culture.

\section{INTRODUCTION}

Management theorists and practitioners recognize corporate culture as one of the most important assets of innovative companies. Culture defines such elements of innovation activity as: features of generation of innovative ideas; criteria for screening out innovative projects; approaches to management and interaction within project groups; principles of group formation, etc. From this, we also conclude that by defining and constructing individual "blocks" of corporate culture, it is possible to strengthen various aspects of innovation activity.

\section{PURPOSE AND OBJECTIVES}

The purpose of the article is to determine the optimal cultural characteristics necessary for the implementation of radical innovative projects. The objectives:

- Identification of the most significant components of culture that affect the innovation process;

- Determining the leading radical innovative companies of our time;

- Analysis of their innovation culture from the point of view of the identified components.

\section{RESEARCH METHODOLOGY}

The most frequently mentioned typologies of corporate cultures in the scientific literature will be presented. The parameters underlying these typologies will be considered as key cultural components that influence the activities of companies. From the list of the largest companies, six units will be selected that have implemented a series of radical innovations, and still retain this ability. From the management literature, well-known business magazines and interviews with the management staff of these companies, the cultural characteristics of each of them will be determined in terms of the selected cultural components. Next, a mathematical probability formula will be used to assess the regularity of the identified results and previously formulated author's theses in the framework of scientific articles.

Thus, the common cultural characteristics of these companies allow us to make a deductive conclusion that the presence of these features is an important condition for the implementation of radical projects for other companies as well. 


\section{THE RESULTS OF THE STUDY}

\subsection{Identification of key components of organizational culture}

Here are the most frequently mentioned authors in the management literature of typologies of corporate cultures and the parameters inherent in them: R. Rutinger (risk tolerance and speed of feedback); Dale and Kennedy (risk and feedback); C. Handy (level of centralization and degree of formalization); K. Cameron and R. Quinn (internal or external focus and degree of flexibility); R. Akoff (involvement of employees in setting goals and choosing means to achieve them). The typologies of Ruttinger and Dale and Kennedy are similar and are based on two identical parameters: risk and feedback. Innovation activity involves high risks of decision-making, in comparison with other industries. In addition, feedback is slow, as innovative projects are always long in time. Thus, these typologies do not require a deeper analysis, and we will analyze the following six parameters: the level of centralization; formalization; internal or external focus; flexibility; access of employees to goal setting and the choice of means to achieve them [1].

Earlier, the authors formulated some theses regarding the cultural characteristics of companies that create radical innovations, related to the listed parameters. Let us list these theses [2;3]:

1. External focus and differentiation are characteristic of radical innovators: adaptability to market conditions, identification and response to industry trends.

2. Flexibility and discreteness of the corporate culture are also characteristic of them, manifested in a high adaptability to external and internal changes.

3. Wide access of junior staff to the choice of funds and resources for the implementation of innovative tasks is necessary, since breakthrough projects involve new tasks that require non-trivial approaches.

\subsection{Identifying the largest companies creating radical innovations}

The Statista portal has compiled a rating of the world's largest companies for 2020 . We will select and analyze the innovative component of these companies, starting from the top lines [4].

Financial companies (banks, insurance and investment funds) are actively represented. This category of institutional units traditionally shows high conservatism in the creation and implementation of innovations. Payment companies from this sector (Paypal, American Express, Visa, Mastercard) are based on innovative technologies, but the evolutionary path of development dominates the revolutionary one.

Food corporations (Coca Cola, PepsiCo, Nestle, P\&G), Mining companies (ExxonMobil, Royal Dutch Shell, Chevron), Retailers (Walmart, Costco, Target, Home Depot) follow a similar strategy, preferring to buy ready-made technologies. The innovative activities of pharmaceutical companies (Pfizer, Novartis, BristolMyers, Merck \& Co) are difficult to assess, since the development of drugs is based on different principles.

The innovative strategy of the largest telecommunications companies AT\&T and Verizon does not involve radical initiatives, but actively responds to industry shifts, such as the introduction of 5G networks. Technology players in the Asian market are also not inclined to introduce breakthrough innovations. So, Alibaba Group and Tencent largely copy the business models of Western trading companies, and Samsung, Toyota, etc. are focused on incremental development. However, a significant share of innovation is concentrated in the technology sector. Let's consider them.

We identify Apple as one of the most consistent generators of breakthrough innovations (tablet PCs, touch smartphones, iTunes, etc.). Microsoft has developed: the user interface, the latest operating systems, and the Visual Studio development environment. Amazon is developing the first cloud service, the latest model for selling e-books. At the moment, the areas with high potential for market transformation are developing: delivery of goods by drones; supermarkets without sellers, etc.

We have previously described Google as an improving innovator. Radical innovations were introduced to the platform Facebook.com at the stage of creation, but the further development of the company follows an evolutionary path [2].

Intel has managed to implement a series of radical technologies in the CPU, but today has difficulty adapting to industry changes. Former Intel CEO Craig Barrett writes that the focus on operational activities hinders the formation of a culture and processes for breakthrough activities. There are also no major breakthroughs in the graphics and central processing industry for a long time, from which we conclude that the main competitors of the company NVidia and AMD are also not radical innovators [5, p.54].

Cisco Systems is a consistent radical innovator in the field of network equipment, and is recognized as such by expert Clayton Christensen. Johnson \& Johnson has the following achievements: a breakthrough in the field of robotic surgery; the creation of disposable lenses; the development of mobile applications for determining blood sugar levels and the presence of allergic reactions of the body, etc., 
Table 1. The components of the organizational culture of breakthrough innovative companies

\begin{tabular}{|l|c|c|c|c|c|c|c|}
\hline \multicolumn{1}{|c|}{ Components } & Apple & Microsoft & Amazon & J\&J & Cisco & Nike & Total number \\
\hline External focus and & $\checkmark$ & $\checkmark$ & $\checkmark$ & $\checkmark$ & $\checkmark$ & $\checkmark$ & 6 \\
\hline $\begin{array}{l}\text { Flexibility } \\
\text { readability }\end{array}$ & $\times$ & $\checkmark$ & $\checkmark$ & $\checkmark$ & $\checkmark$ & 5 \\
\hline Centralization & $\checkmark$ & $\checkmark$ & $\checkmark$ & $\times$ & $\times$ & $\times$ & 3 \\
\hline Formalization & $\times$ & $\checkmark$ & $\times$ & $\checkmark$ & $\checkmark$ & $\checkmark$ & 4 \\
\hline $\begin{array}{l}\text { Selection of targets by } \\
\text { staff }\end{array}$ & $\times$ & $\times$ & $\checkmark$ & $\times$ & $\checkmark$ & $\times$ & 2 \\
\hline $\begin{array}{l}\text { Choosing the means of } \\
\text { achievement }\end{array}$ & $\checkmark$ & $\checkmark$ & $\checkmark$ & $\checkmark$ & $\checkmark$ & $\checkmark$ & 6 \\
\hline
\end{tabular}

which also allows us to assign it to the desired category of innovators [6, p.291].

Sports Shoe manufacturer Nike has implemented the following revolutionary technologies: Air Max, Zoom Air, Foamposite Technology, Converse-Helium Technology.

So, the following companies, according to our analysis, are radical developers: Apple, Microsoft, Amazon, J\&J, Cisco and Nike.

\subsection{Analysis of organizational cultures}

Apple has a tightly centralized structure, goalsetting comes from top management, but there is freedom and a wide choice of means to achieve them. Matt Assay, the former head of the business development department, describes the attitude towards personnel as follows: "Ignoring the hierarchy, the company is focused on results, and employees are a key partner in achieving the goals set" [7, p.70].

Apple has a high adaptability to the market, satisfying, among other things, not so obvious consumer preferences. The Apple analyst compares the approaches taken in it with Microsoft: "Apple has a culture of creativity, combines flexibility and sensitivity to the external environment", "Microsoft employees are extremely rational and used to carefully weigh economic decisions" [8, p.176].

Microsoft is characterized by excessive bureaucratization of processes. Goals are set by the top levels of the hierarchy. "A culture has been formed that prevents the birth of new ideas that put the order of things in the company at risk," writes the company's analyst. Nicholas Smith, the head of R\&D, says: "The main flaw in the company's culture is the lack of adequate support for the autonomy of project teams, thanks to which the staff could implement their own ideas." Another employee, Hesham Essam, says that many tools and opportunities are available to help effectively solve goals and objectives [9, p.53; 10].

Amazon's culture has some similarities to Apple's, being just as centralized at the head of the company level. This is partly reflected in the company's strict personnel policy. At the same time, the HBR source states some elements of decentralization, manifested in the ability of employees to initiate their projects. These projects must be approved by the CEO. The management in an interview with the New York Times calls the company's management style a meritocracy that encourages competition between people and their initiatives [11,12].

The company is also distinguished by weak bureaucratic barriers. The innovative magazine Fastcompany describes one example of the initiation of a project by ordinary employees: two ordinary employees discussed the idea of transporting goods by means of drones, they immediately began to implement it in the laboratory on existing equipment. Six months later, they showed the finished prototype to the head of the company and received approval for the development of the project. Thus, the staff has both goal-setting capabilities and appropriate tools to achieve them [13].

K. Christensen writes about Johnson \& Johnson's operations: "The company's strategy is to launch breakthrough products through acquired small firms." This creates a very flexible corporate culture, which can vary significantly from one division to another. Companies are given autonomy both in goal setting and in choosing the necessary funds. At the same time, cultural elements of the main structure are introduced in order to preserve the cultural identity of the corporation [14, p.274; 15, p.244].

For Cisco Systems valued ideas and initiatives are coming from the staff. For these purposes, a digital corporate platform ("ideas zone") has been created. Managers are committed to providing resources and 
full support for the implementation of ideas [16, p.174; 17].

A "task culture" has been built: the structure is decentralized, and the reward system supports teamwork and keeps the work manageability at the proper level. In an interview, the manager said that it is impossible to introduce active interaction while maintaining autocracy. According to Forbes, the company aims to be a "mirror of the market", showing sensitivity to consumer preferences. The basic cultural feature is the desire for diversity of personnel in cultural, social and other aspects [18, p.163].

A well-known expert in the field of management A. Rotaker notes that Nike is one of the few companies that have not lost their entrepreneurial culture with increasing scale. Initiatives of ordinary employees are encouraged, and the company structure is based on the autonomy of project teams. The authors of breakthrough technologies in sports shoes indicated that they were given a wide scope, resources and leadership support in implementing their ideas [19, p.13, 151].

The analyst of HBR magazine speaks about the firm orientation of the company to the market. The company's motto is "stay flexible and adaptive and challenge the status quo." Fortune magazine and Comparably portal confirmed the company's commitment to cultural diversity through statistical research $[20,21]$.

So, we systematize the data obtained in tabular form (table 1.).

The property of external focus and differentiation and high availability of funds to achieve goals are characteristic of all 6 companies, and the property of flexibility and discreteness of 5 companies out of 6 . Mathematically, we will determine whether these figures should be considered natural, if we assume that the probability of falling out of the chosen value from two opposite values, which each of the cultural parameters has, is $50 \%$, all other things being equal.

So, let's calculate first the probability of matching 6 out of 6 paragraphs $\left(P_{1}\right)$, and in the second stage of the calculations, 5 points from $6\left(P_{2}\right)$, applying the formula of probability Bernoulli, despite the fact that $n$ is the number of equally possible outcomes, $m$ is the number of matches indicated by the results of table, $p$ is the probability of one of the two opposite properties of these parameters, $q=1-p, n=6 ; m=6 ; p=0,5 ; q=$ 0.5 .

$P_{n}(m)=\left(C_{n}^{m}\right) p^{m} q^{n-m}=\frac{6 !}{(6-6) ! 6 !} 0.5^{6} 0.5^{6-6}=$ 0.01562

$P_{1}=1-0.01562 \approx 0.984=98.4 \%$
We calculate the probability of falling out 5 times out of 6 of one of the parameters we specified, for $n=6$; $m=5 ; p=0.5 ; q=0.5$.

$P_{n}(m)=\left(C_{n}^{m}\right) p^{m} q^{n-m}=\frac{6 !}{(6-5) ! 5 !} 0.5^{5} 0.5^{6-5}=$ 0.09375

$P_{2}=(1-0.01562)(1-0.09375) \approx 0.892=$ $89.2 \%$

\section{THE INTERPRETATION OF THE CALCULATIONS. CONCLUSIONS}

Successful companies that consistently introduce radical innovations are characterized by the following cultural characteristics: external focus and differentiation, manifested in active work to identify and meet market needs, identify market and industry trends, effectively interact with external contractors; providing junior staff with broad access to available resources for the implementation of designated goals and objectives. The availability of such access and the absence of significant formalized obstacles is necessary, since radical projects involve the solution of many new and non-trivial tasks. The veracity of each of these statements is proven with a probability of $98.4 \%$.

For today's radical innovative companies, it is vital to remain focused on the market and the external environment. The isolation of intra-organizational processes and the inertia of development indicate the onset of the aging stage of the life cycle of companies.

The thesis about the need for differentiation of project groups was confirmed with a probability of $89.2 \%$. This item corresponds to the indicator of flexibility and discreteness. The reason is that the diversity of professional and cultural experiences stimulates the creative process of groups, which is so important when faced with new challenges.

The formation of these cultural components is a necessary measure for developing the ability to implement radical innovative projects. The results can be valuable for the management of companies that intend to develop breakthrough products, processes and business models.

\section{FUNDING}

The research was carried out with the financial support of the RFBR in the framework of scientific project No. 20-310-90066 


\section{REFERENCES}

[1] V.D. Pak, N.I. Nuzhina, Basic typologies of organizational culture, International research journal Iss. 8(27) Part 3 (2014) 50-53 (In Russ.).

[2] Z.K. Tavbulatov, I.O. Sulumov. Identification of optimal characteristics of management of radical innovative projects, Financial bases of investment activity of the region: state and problems of formation, 2016, pp. 434-438, IE Ovchinnikov Mikhail Arturovich. Makhachkala (In Russ.).

[3] Z.K. Tavbulatov, I.O. Sulumov. Identification of the most important regularities and characteristic features of the radical innovation process, Innov: electronic scientific journal Iss. 4(29), 2016 (In Russ.).

[4] E. Duffin, The 100 largest companies in the world by market capitalization in 2020. Retrieved from: https://www.statista.com/statistics/263264/topcompanies-in-the-world-by-market-capitalization/

[5] P. Formica, M. Curley, Exploring the Culture of Open Innovation: Towards an Altruistic Model of Economy. Bingley: Emerald Group Publishing, 2018. p. 264.

[6] C. Christensen, M. Raynor, The Innovator's Solution: Creating and Sustaining Successful Growth. Boston: Harvard Business Review Press, 2013. p. 320.

[7] D.K. Bhattacharyya, Cross-Cultural Management: Text and Cases. New Delhi: PHI Learning, 2010. p. 344 .

[8] L. Thompson, The Truth About Negotiations. FT Press, 2013. p. 216.

[9] M. McQueen, Momentum: How to Build it, Keep it or Get it Back. Hoboken: John Wiley \& Sons, 2016. p. 232.

[10] What is the corporate culture like at Microsoft? How is the culture different than other companies? Retrieved from: https://www.quora.com/What-isthe-corporate-culture-like-at-Microsoft-How-isthe-culture-different-than-other-companies

[11]D. McGinn, How Jeff Bezos Makes Decisions. Retrieved from: https://hbr.org/2013/10/how-jeffbezos-makes-decisions

[12] J. Kantor, D. Streitfeld, Inside Amazon: Wrestling Big Ideas in a Bruising Workplace. Retrieved from:

https://www.nytimes.com/2015/08/16/technology/ inside-amazon-wrestling-big-ideas-in-a-bruisingworkplace.html
[13]Carr, Gur Kimchi and Daniel Buchmueller. Retrieved from: https://www.fastcompany.com/3029167/gurkimchi-and-daniel-buchmuellera

[14] A.J. DuBrin, Essentials of Management. Boston: Cengage Learning, 2008. p. 652.

[15] W. Lazonick, American Corporate Economy: Critical Perspectives on Business and Management, Didcot: Taylor \& Francis Vol. 4 (2002) 440 .

[16] M.R. Czinkota, I.R. Ronkainen, International Marketing, Boston: Cengage Learning, 2013, p. 720.

[17] P. Moorhead, How Cisco Fosters A 'Conscious Culture' Within The Company. Retrieved from: https://www.forbes.com/sites/patrickmoorhead/20 19/03/19/how-cisco-fosters-a-conscious-culturewithin-the-company/\#3530d38250b7

[18] M.T. Hansen, Collaboration: How Leaders Avoid the Traps, Create Unity, and Reap Big Results, Boston: Harvard Business Press, Boston, p. 231.

[19] J. Kell, Majority of Nike's U.S. Employees Are Minorities for the First Time. Retrieved from: https://fortune.com/2016/05/12/nike-staffdiversity/

[20]Diversity at Nike. Retrieved from: https://www.comparably.com/companies/nike/div ersity

[21] G.E. Willigan, High-Performance Marketing: An Interview with Nike's Phil Knight. Retrieved from: https://hbr.org/1992/07/high-performancemarketing-an-interview-with-nikes-phil-knight 